our findings are not peculiar to Newcastle berg and her colleagues (17 October, p. 142) for the same high incidence of jejunal was that "no difference was found between mucosal abnormalities has been found in the average depression scores of the oral large series from London ${ }^{14,15}$ and Glasgow ${ }^{16}$ contraceptive and the control groups." I and several cases have been reported from would have liked to have seen as much

This means that all patients with dermatitis herpetiformis should be investigated for coeliac disease solely on the grounds that they have dermatitis herpetiformis. The evidence is now so unequivocal that the day may not be far off when any of us may be called to answer a charge of negligence if we omit this essential investigation.-We are, etc.,

JANET MARKS SAM SHUSTER

Department of Dermatology

Newcastle upon Tyne.

1 Shuster, S., and Marks, J., Systemic Effects of Skin Disease, $\mathrm{D}$. 81 , Heinem 2 Robinson, D. C. C.' Personal Communication, 1970 cal Association fournal, 1968, 98, 575 .

Fraser, N. G., Ferguson, A., and Murray, D. British Medical fournal, 1968, 4, 30

6 Inman, P., Personal Communication, 1970.

Wilkinson, D. F., Personal Communication, 1970.
Marks, J., Shuster, S., and Watson, A. J., Lancet, 1966,2 , 1280 .

Shuster, S., Watson, A. J., and Marks, J., Lancet, 1968, 1 , i 1101 .

Shuster, S., and Marks, J., Proceedines of the

Marks, J., and Shuster, S., Proceedings of the International Conference on Coeliac Disease,

1969, in press.
Watson, A. J., Shuster, S., and Marks. J., Modern
Gastroenterology, Procedings of VIIT, Modert Gastroenterology. Proceedines of VIIIth Inter-
nazional Congress of Gastroenterology, p. 798, 1969.

12 Marks, J., and Shuster, S., Gut. 1970, 11.281.

logy, $1970,101.452$.

Fry, L., Kier. P.. McMinn, R. M. H., Cowan,
I. D., and Hoffirand, A.' V., Lancet, 1967,

Marks, R., Whittle, M. W.. Beard. R. T., Robert-

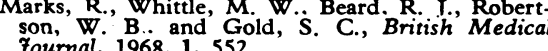
Fraser $N$ G

I. O'D., British Ұournal of Dermatology, 1967, 79. 509.
Vingeren, J. H. M., Van der Staak,
W. T. B. M., and Schillings, P. H. M., Lancet, W. I. B. M., and Schillings, P. H. M., Lancet,
1967. 1. 218. 18 Brow, J. R., Parker, F., and
enterology, 1968, 54, 1223 .

\section{Depression and Oral Contraception}

SIR,-One factor that has not been mentioned in the discussion on oral contraceptives and depression is the high incidence of depression occurring in women following childbirth. These no doubt form a sizeable proportion of women attending family planning clinics and the majority of those receiving birth control advice in my own practice.

Pitt $^{1}$ found that $10 \%$ of women delivered at a London teaching hosnital suffered from postpartum depression. More recently. Miss Sylvia Lutkins and $\mathrm{I}^{2}$ used the Beck Depression Inventory to assess the incidence of depression associated with childbirth. At a cutting score of 17, the incidence of moderately severe depression was $10 \%$, which is similar to the finding of Pitt. We also found that throughout the 12-month period following childbirth the incidence of moderately severe depression was constant at $10 \%$, with about $3 \%$ of mothers severely depressed. (Incidentally, during the antenatal period $9 \%$ of mothers are moderately depressed and 3\% severely depressed, while the before and after rate for moderate depression among fathers remains constant at $3 \%$.)

The finding that particularly interested me in the paper by Dr. Brenda N. Herzemphasis given to this finding as given to the fact that $6.6 \%$ of those taking oral contraceptives were severely depressed. The latter finding surprises me perhaps less than the former as, from my own use of the Beck Depression Inventory, I expect about $3 \%$ of women receiving contraceptive advice from me to be severely depressed at the first interview.-I am, etc.,

Llanidloes, Mon

Dewi ReEs

1 Pitt, B., British fournal of Psychiatry, 1968, 114, Rees, W. Di, and Lutkins, S. G., Fournal of the
Royal College of General Practitioners, in press.

\section{Cystic Degeneration of the Popliteal Artery}

SIR,-Your leading article on this subject (19 December, p. 699) is a good review of this uncommon cause of intermittent claudication in young adults. Only one point of practical importance should perhaps be added. While it is likely that most cases will go unrecognized until arteriography or operation show the typical lesion, which at once distinguishes itself from the commoner obstructions due to arteriosclerosis or Buerger's disease-that is, in the $70 \%$ or so smoke cigarettes-yet when the cystic lesion (or popliteal entrapment for that matter) brings about claudication in one of the nonsmoking $30 \%$ a non-arteriosclerotic cause should be suspected. Such a case was diagnosed clinically, even before arteriography, in my report some years ago. ${ }^{1}$ The incidence of non-smoking in male claudicators in my experience remains, as it was then, about $1 \%$.-I am, etc.

London N.W.1

H. H. G. Eastcott

1 Eastcott, H. H. G., Lancet, 1962, 2, 1117.

\section{Spontaneous Rupture of Spleen}

SIR,-I wish to report a case of spontaneous rupture of a normal spleen. Traumatic rupture of the spleen is very common while spontaneous rupture of a pathological spleen, although rare, is well documented especially in tropical diseases such as malaria and kala-azar where the spleen may be markedly enlarged. Spontaneous rupture of a normal spleen, however, is extremely rare.

A 55-year-old housewife was admitted to hospital as an emergency with abdominal pain of one week's duration. The latter was a constant dull ache in the left hypochondrium coughing. There was no shoulder pain. She was certain that she had not sustained any injury. On examination she was very pale but not in pain. The relevant abnormal finding were a pulse of 120 per min.; an abdomen which was soft but with slight tenderness on deep palpation in the left hypochondrium; haemoglobin of $5 \mathrm{~g} / 100 \mathrm{ml}$; and a reticulocyte count of $7 \cdot 2 \%$. A barium meal a few days after admission showed a large filling defect in the fundus of the stomach very suggestive of a carcinoma.

The patient was transfused with packed cells and 12 days later a laparotomy was performed A very large perisplenic haematoma was found of this age group of the population who markedly accentuated by deep breathing and by pushing the fundus of the stomach medially and forwards but otherwise the stomach was normal. There was about $300 \mathrm{ml}$ of dark altered blood in the peritoneal cavity. The haematoma was separated easily from the stomach, left dome of the diaphragm, and abdominal wall, and in its centre was a normal-sized spleen showing a laceration extending into the splenic parenchyma. The spleen and the surrounding haematoma were removed and a liver biopsy was performed although the liver was not enlarged. No other abnormality was found in the peritoneal cavity. Histology showed a normal spleen and liver.

To exclude the diseases with which spontaneous rupture of the spleen has been associated we did repeated blood counts, bone marrow examination, plasma proteins and electrophoretic pattern, and Paul-Bunnell test, and these were all normal. She has now been followed up for over a year and remains well with a normal blood count. During the postoperative period the patient was questioned closely by different people and she was absolutely certain that she had not sustained any injury, however slight, in the preceding few weeks.

This case differs from the other reported cases of spontaneous rupture of the normal spleen in that our patient did not present with the clinical picture of bleeding into the peritoneal cavity, as is normal, but instead presented as anaemia due to carcinoma of the stomach-a very misleading presentation of an extremely rare condition.- I am, etc.,

Redhill, Surrey

A. Grech Redhill General Hospital,

\section{Home Haemodialysis}

SIR,-Much has been written about the difficulties of initiating haemodialysis in the home and the time-consuming frustrations that take place between the hospital and the local authority in setting up this urgent life-saving service. It is both disturbing and frightening to read that these frustrations exist in view of the detailed guidance given to local authorities by Ministry of Health Circular issued in August 1968. ${ }^{1}$

In the district for which I am responsible there is a very simple and immediate working relationship between my department and the hospital dialysis team. As soon as it is found necessary for a patient to have home dialysis the administrator of the hospital dialysis team immediately contacts the owner of the property for permission to install equipment and adapt to the necessary requirements. Once this permission is given I am consulted in order that the adaptation work can be finalized within the provisions of Section 28 of the National Health Service Act 1946. My council is conscious of the necessity for urgent provision of all types of service covered by Section 28 and has had the foresight to delegate to its medical officer of health the giving of approval subject to availability of finance within the annual estimate. There is no valid reason for delay while awaiting committee consent.

It has been found advantageous to employ where possible the same local building contractor, who is fully aware of the building regulations and who will advise if any planning consent is required. Any such problem is then quickly resolved at local authority officer level. My records show that the time taken from first request to 